\title{
O ENTENDIMENTO JURISPRUDENCIAL DO TRIBUNAL DE JUSTIÇA DO RIO GRANDE DO SUL SOBRE O FORNECIMENTO JUDICIAL DE MEDICAMENTOS
}

\section{THE JURISPRUDENTIAL UNDERSTANDING OF THE RIO GRANDE DO SUL COURT OF JUSTICE ON THE JUDICIAL SUPPLY OF MEDICINES}

\author{
Guilherme Pavan Machado* \\ José Carlos Kraemer Bortoloti**
}

\begin{abstract}
Resumo: A crescente Judicialização chama atenção ao passo que denuncia a inefetividade das políticas públicas, bem como impacta no entendimento do tribunal referente à demanda judicial pleiteada. Indubitavelmente, o direito fundamental à saúde é objeto de um contingente considerável da Judicialização, muito em razão do préstimo deficiente das instituições. Sabe-se que o direito à saúde tem previsão constitucional e infraconstitucional, atribuindo a responsabilidade ao Estado para sua realização por meio de políticas públicas e programas de governo. Contudo, a via administrativa-executiva estatal encontra dificuldades na efetividade desse direito a todos os indivíduos, na verdade não atende satisfatoriamente a população. Diante desse cenário, a alternativa subsidiária torna-se a Judicialização da pretensão, ou seja, o cidadão, objetivando a tutela do seu pleito à saúde busca-o na prestação jurisdicional. Nesse sentido, o presente trabalho tem como objetivo delinear o direito fundamental à saúde no entendimento do Tribunal de Justiça do Estado do Rio Grande do Sul, especificamente nas demandas de pleito de medicamentos. Por meio da pesquisa qualitativa técnica de revisão bibliográfica e do estudo de julgados no TJRS, utilizando do método fenomenológico-hermenêutico, buscar-se-á delinear o entendimento do referido tribunal, em grau de apelação, referente ao fornecimento judicial de fármacos pelo Estado, como forma de compreender quais são as variantes que direcionam o (não) deferimento da pretensão judicial do indivíduo e como o direito à saúde se apresenta neste cenário jurisprudencial.
\end{abstract}

Palavras-chave: Direito Fundamental à Saúde; Judicialização; Tribunal; Jurisprudência; Medicamentos.

Abstract: The increasing judicialization calls attention to the step that denounces the ineffectiveness of public policies, as well as impacts on the court's understanding

\footnotetext{
* Mestrando em Direito pela Faculdade Meridional IMED, na linha de pesquisa Fundamentais do Direito e Democracia. Membro do Grupo de Pesquisa: Direitos Fundamentais, hermenêutica e proporcionalidade: crítica ao desenvolvimento prático-teórico do dever de proteção aos Direitos Fundamentais. Bacharel em Direito pela Faculdade Meridional IMED. Advogado. E-mail: guilherme.machado@imed.edu.br.

*** Doutor em Direito (UNESA/RJ), com Doutoramento Sanduíche junto à Faculdade de Direito da Universidade de Lisboa (orientação Prof. Dr. Jorge Miranda) financiado pelo PDSE/CAPES. Mestre em Direito (ULBRA/RS). Advogado. Atualmente faz parte do Corpo Docente da Escola de Direito da Faculdade Meridional - IMED, na Coordenação do NUJUR e no NDE do Curso. Pesquisador do Núcleo de Pesquisa Dignidade, Estado e Direito e do Grupo de Pesquisa Direitos Fundamentais e Novos Direitos, ambos do PPGD Stricto Sensu da Universidade Estácio de Sá (UNESA/RJ); membro do Centro de Estudos e Pesquisas em Estado, Jurisdição e Direitos Fundamentais (CEPEJuD) da Escola de Direito da Faculdade Meridional (IMED/RS). E-mail: jose.bortoloti@imed.edu.br.
} 
regarding the lawsuit filed. Undoubtedly, the fundamental right to health is the subject of a considerable contingent of judicialization, largely because of the inadequate facilities of the institutions. It is known that the right to health has constitutional and infraconstitutional foresight, assigning responsibility to the State for its fulfillment through public policies and government programs. However, the state administrativeadministrative route finds difficulties in the effectiveness of this right for all individuals, in fact does not satisfactorily serve the population. In view of this scenario, the alternative alternative becomes the judicialization of the claim, that is, the citizen, aiming to protect his claim to health seeking it in the jurisdictional provision. In this sense, the present work aims to outline the fundamental right to health in the understanding of the Court of Justice of the State of Rio Grande do Sul, specifically in the lawsuits for drug litigation. Through the qualitative technical research of bibliographic review and the study of judgments in the TJRS, using the phenomenological-hermeneutic method, it will be sought to delineate the understanding of said court, in degree of appeal, regarding the judicial supply of drugs by the State, as a way of understanding which are the variants that direct the (non) deferment of the judicial claim of the individual and how the right to health presents itself in this jurisprudential scenario.

Keywords: Fundamental Health Law; Judiciary; Court; Jurisprudence; Medicines.

\section{INTRODUÇÃO}

O presente trabalho tem como objetivo delinear o direito fundamental à saúde no entendimento do Tribunal de Justiça do Estado do Rio Grande do Sul (TJRS), uma vez que a Judicialização se tornou um protagonista no cenário jurídico brasileiro, especialmente do direito fundamental à saúde, ao passo que deveria ser coadjuvante das políticas públicas.

Com base nessa problemática da Judicialização da política, e a preocupação de como os tribunais, em destaque nesse trabalho científico o TJRS, vem decidindo e se posicionando na efetividade desse direito fundamental, buscar-se-á analisar sucintamente alguns acórdãos de apelação cível referente ao fornecimento de medicamentos, onde será possível analisar as variantes que coadunam o entendimento dos desembargadores em segunda instância.

Preliminarmente, com a finalidade de direcionar o debate principal, o direito fundamental social ${ }^{1}$ à saúde vem, primeiramente no texto constitucional, expresso no artigo $6^{\circ}$, dentro do título "Dos direitos e garantias fundamentais", que disciplina a gama de direitos fundamentais previstos, num rol exemplificativo, em razão da abertura do $\operatorname{artigo~} 5^{\circ}, \S 2^{\circ}$ da Constituição Federal. O constituinte, ao consagrar o direito à saúde como fundamental, de pronto lhe atribui importância diferente no ordenamento jurídico brasileiro, em razão do papel dos direitos fundamentais como um todo no Estado 
O entendimento jurisprudencial do Tribunal de Justiça do Rio Grande do Sul sobre o fornecimento judicial de medicamentos

Democrático (e Social) de Direito. Por conseguinte, os artigos 196, 197, 198, 199 e 200 da $\mathrm{CF} / 88$ destinam atenção especial para a saúde, apontando os princípios estruturantes e atribuições do Sistema Único de Saúde, bem como formas de financiamento pela União, Estados e Municípios ${ }^{2}$.

O texto de maior importância nessa seção (Seção II, capítulo II do Título VIII da $\mathrm{CF} / 88$ ) é o disposto no artigo 196, que das suas disposições pode-se extrair seis aspectos importantes: a) direito de todos, portanto, de toda e qualquer pessoa, brasileiro ou estrangeiro; b) dever do Estado, cabendo precipuamente ao Estado a efetividade desse direito; c) mediante políticas públicas, sendo essa modalidade a primeira forma a ser realizada para efetividade e realização da saúde; d) visando a redução de doenças e agravos; e) acesso universal e igualitário, portanto, não seletivo; e f) para a promoção, proteção e recuperação, três constantes almejadas pelo sistema único de saúde.

E mediante atuação estatal pela via administrativa-executiva que deve o Estado garantir a efetividade do direito à saúde. No entanto, uma vez que o direito à saúde, enquanto dotado das peculiaridades dos direitos fundamentais como aplicabilidade imediata $^{3}$ e ser direito subjetivo ${ }^{4}$, dá azo para que o cidadão busque a prestação jurisdicional para tutela do seu direito.

\section{A NECESSÁRIA RELAÇÃO ENTRE A JUDICIALIZAÇÃO DA POLÍTICA E AS RESPOSTAS DA JURISDIÇÃO}

\subsection{A Judicialização da Política}

O fenômeno da Judicialização da política, tratando aqui de modo delimitado do direito fundamental social à saúde, ganhou contornos inimagináveis pelos ministros do STF e STJ e até mesmo pelos juízes das instâncias inferiores. As demandas envolvendo a tutela de medicamentos, cirurgias e outros provimentos de ordem sanitária despencaram sobre a mesa dos magistrados, corroborando inúmeros pontos anteriormente traçados, como o aumento da jurisdição constitucional, adotada pelo constituinte da $\mathrm{CF} / 88$, embasada na busca de efetividade do texto constitucional e na centralidade dos direitos fundamentais (BARROSO, 2012, p. 15), e da inefetivadade das políticas públicas, meio primeiro de satisfação dessas demandas.

A Judicialização, para Barroso $^{5}$ (2012), decorre de três grandes causas: a) a redemocratização; b) a constitucionalização abrangente; e c) o modelo de controle de constitucionalidade adotado. 
A redemocratização do Estado surge tardiamente no Brasil, somente com o advento da Constituição de 1988, e tem como propósito primeiro a limitação do poder estatal e a proteção dos direitos fundamentais do homem. Isso levou a um Poder Judiciário mais atuante, protagonista de decisões políticas, e guardião da Constituição, que passou a ser o centro de validade do ordenamento jurídico brasileiro, cabendo ao Legislativo observância às normas constitucionais para atividade legiferante, e condicionador dos atos e programas políticos do Poder Executivo. Ainda, revitalizou a democracia ao passo que aumentou o "[...] o nível de informação e de consciência de direitos a amplos segmentos da população, que passaram a buscar a proteção de seus interesses perante juízes e tribunais" (BARROSO, 2012, p. 24).

A constitucionalização abrangente ou constitucionalização do direito é, na verdade, a opção do constituinte em dar a Constituição um caráter maximizador ${ }^{6}$ e promissória, ou seja, trouxe para dentro do texto constitucional matérias anteriormente desenvolvidas unicamente na seara política, a exemplo dos direitos sociais, especificamente o direito à saúde. $\mathrm{O}$ efeito dessa constitucionalização abrangente é o aumento das possibilidades de exigências judiciais de direitos, pois, uma vez que relações sociais ou políticas tornam-se normas constitucionais, gozando dos privilégios a elas inerentes, “[...] ela se transforma, potencialmente, em uma pretensão jurídica, que pode ser formulada sob a forma de ação judicial” (BARROSO, 2012, p. 24).

E por fim, o terceiro item diz respeito ao controle de constitucionalidade adotado pelo texto constitucional brasileiro de 1988, considerado uma combinação do modelo americano e europeu, bem como o mais abrangente do mundo. Isso porque deu aos juízes e tribunais a decisão de declarar a inconstitucionalidade da lei, e assim deixar de aplicá-la (controle difuso), ao passo que também concentrou nas mãos do Supremo Tribunal Federal (STF) essa possibilidade de decidir a inconstitucionalidade, o descumprimento de preceito fundamental, a constitucional, a inconstitucionalidade por omissão de dispositivo constitucional, tudo isso somado ao rol de legitimados para a propositura dessas ações, constante no artigo 103 da Constituição Federal.

Especificamente no tocante a comunhão da Judicialização e do direito fundamental social à saúde, muito ainda se discute. Porque as políticas públicas de fornecimento de medicamentos, por exemplo, são ineficientes, são má geridas, e não satisfazem a expectativa de direito do cidadão, não conseguindo concretizar o direito fundamental à saúde naquele aspecto. Assistindo seu direito à saúde lesado, não ofertado ou ofertado aquém, e atrelado aquele maior nível de informação proveniente de uma 
O entendimento jurisprudencial do Tribunal de Justiça do Rio Grande do Sul sobre o fornecimento judicial de medicamentos

redemocratização, o cidadão busca o Poder Judiciário para exigi-lo judicialmente. Não são raros os casos. O Rio Grande do Sul, em matéria veiculada no sítio Consultor Jurídico, é o estado brasileiro que lidera o ranking de demandas de tutela de saúde, com aproximadamente 113 mil processos, seguido por Minas Gerais com 66,7 mil processos ${ }^{7}$.

A magnitude que a Judicialização da saúde tomou fez necessário a convocação da Audiência Pública, em 2009, que será abordada no próximo item, entretanto, de há muito vem sendo denunciado o crescimento acelerado das "[...] decisões judiciais em matéria de saúde [...]" (FERREIRA, 2011, p. 238), especificamente, a partir da década de 90.

Nesse cenário, é imprescindível destacar a emblemática decisão de relatoria do Ministro Gilmar Mendes, na Suspensão de Tutela Antecipada n. 175, formulada pela União em face de acórdão do Tribunal Regional Federal da $5^{\text {a }}$ Região, nos autos da apelação cível n. 408729 do Ceará, que buscou determinar alguns aspectos que devem ser observados na tutela jurisdicional, assim como argumentos que são frequentemente ventilados nesse tipo de demanda (BRASIL, 2009). O conteúdo da decisão, no sentido de elencar aspectos importantes do provimento jurisdicional do direito à saúde, deve ser observada pelos tribunais inferiores com a finalidade de dar harmonia a jurisprudência nacional.

De certo, a Judicialização da saúde não é tema pacífico no cenário jurídico brasileiro, muitas são as objeções a essa prática $^{8}$, no entanto, amparado pelo ideal constitucional adotado pela Constituição de 1988, pelo caráter fundamental do direito à saúde, bem como pela constante busca de efetividade constitucional, além de outros fatores importantes, como o direito à saúde enquanto direito subjetivo eivado de uma constitucionalização abrangente, fundamentam a possibilidade de Judicialização da saúde como forma de efetividade do texto constitucional ${ }^{9}$.

\subsection{O Desenho Jurisprudencial do Tribunal de Justiça do Estado do Rio Grande do Sul (TJRS) sobre o Fornecimento Judicial de Fármacos}

Esse tópico será destinado para uma análise da jurisprudência do Tribunal de Justiça do Estado do Rio Grande do Sul (TJRS) sobre o direito à saúde nas demandas de fornecimento de medicamentos.

Para tanto, para a realização da busca das decisões foi criado um parâmetro de pesquisa, com a finalidade de compor a metodologia de análise na sequência 
apresentado. Nesse sentido, foi pesquisada jurisprudência no sítio do Tribunal do Rio Grande do $\mathrm{Sul}^{10}$, com as palavras-chave "direito à saúde" e "fornecimento de medicamentos", combinadas, bem como foi delimitado o período de julgamento do dia 01 de fevereiro de 2016 a 29 de fevereiro de 2016, assinalando as opções de decisões colegiadas, acórdãos, e apenas apelações cíveis.

A justificativa para delimitação de tal modo se deu em razão do grande número de decisões que seriam encontradas em uma busca mais ampla, em um período de tempo maior, o que inviabilizaria a análise detida e a exposição adequada dos resultados auferidos.

O resultado foi equivalente a 68 decisões para análise, sendo realizado novo filtro para exclusão de decisões eminentemente processuais e que não se relacionam com o objeto do estudo, alcançando, por fim, um proveito de 53 decisões a serem analisadas ${ }^{11}$.

A análise das decisões se deteve aos seguintes aspectos: a) os temas presentes nas decisões analisadas; b) a incidência ou não incidência desses temas/teses no parecer do acórdão, ou seja, o acolhimento dessa tese por partes dos desembargadores.

A tabela que será abaixo colacionada traz três dados importantes do estudo dos aspectos delimitados anteriormente: a) os temas que estiveram presentes na decisão (por exemplo, responsabilidade solidária dos entes federados, reserva do possível, etc.); b) a quantidade de vezes que esse tema apareceu nas decisões; e c) a incidência ou não, ou seja, a tese abordada incidiu ou foi acolhida pelo desembargador, buscando esclarecer o posicionamento do Colegiado sobre aquele tema/tese.

\section{TABELA 1 - INCIDÊNCIAS DE TEMAS NAS DECISÕES ANALISADAS}

\section{Tema presente na decisão analisada (quantidade de vezes que foi encontrada nas decisões)}

Responsabilidade solidária dos entes federados para o fornecimento do fármaco (28)

Prevalência pela prescrição de médico que assiste cotidianamente a paciente, em detrimento do parecer de médicos assistentes e afins (9)

Afronta aos princípios da universalidade e isonomia do SUS (3)

Fixação de astreintes para coação da Fazenda Pública no cumprimento da determinação judicial (1)

Prevalência das questões organizacionais do SUS

(listagem de medicamentos de responsabilidade de cada ente e questões de competência) (5)
Incidência*

28

9

1

0

0
Não incidência

0

0

1

5 
O entendimento jurisprudencial do Tribunal de Justiça do Rio Grande do Sul sobre o fornecimento judicial de medicamentos

Fornecimento de medicamento conforme Denominação Comum Brasileira (2)

ocasionando indeferimento do pleito (5)

Princípio da Separação dos Poderes (6)

Teoria da Reserva do Possível (7)

Dotação orçamentária como justificativa para não deferimento da pretensão do autor (6)

Cerceamento da defesa dos entes em razão de ausência de intimação do médico assistente para se manifestar sobre eficácia dos medicamentos pleiteados (4)

Preferência pelos medicamentos disponibilizados no SUS e a possibilidade de substituição (14)

Bloqueio de valores das contas dos entes para realização de determinação judicial de fornecimento

Comprovação da hipossuficiência do autor como meio para atender a prestação jurisdicional

Medicamento pleiteado na lista no SUS não exime os entes federados ao fornecimento (2)

Comprovação de real necessidade do tratamento pleiteado (16)

Presunção de eficácia dos medicamentos disponibilizados pelo SUS (prova em contrário ônus do autor) (4)
2

5

0

Fonte: Tribunal de Justiça do Rio Grande do Sul, Criação própria.

* O número de incidência e não incidência será expressado em números, que significaram a incidência ou não do tema/hipótese na decisão analisada.

Assim, para um melhor aproveitamento do presente artigo, alguns dos temas mais incidentes e mais importantes serão profundamente desenvolvidos. Serão abordados quatro tópicos: a) A responsabilidade solidária dos entes federados para o fornecimento dos fármacos; b) Prevalência das questões organizacionais/administrativas do SUS; c) Ineficácia do tratamento postulado pelo cidadão, ocasionando indeferimento do pleito; e d) Teoria da Reserva do Possível e princípio da Separação de Poderes. 


\subsubsection{A Famigerada Responsabilidade Solidária dos Entes da Federação}

A responsabilidade solidária dos entes federados no fornecimento de medicamentos foi o tema mais incidentes nas decisões analisadas, assim como teve unanimidade no acolhimento pelo Tribunal de Justiça do Rio Grande do Sul, ou seja, os entes federados respondem solidariamente a pretensão de fornecimentos de medicamentos pleiteada pelo cidadão.

O conceito de responsabilidade solidária pode ser retirado do Direito Civil, podendo ser definida como a obrigação solidária dos entes federados para com o cidadão, sendo que esse último pode cobrar de qualquer um deles pois todos responsáveis pelo todo devido. Analogicamente para o tema dos medicamentos, União, Estados, Distrito Federal e Municípios são igual e solidariamente responsáveis pelo fornecimento de medicamentos ou então prestação ou realização do direito à saúde aos cidadãos.

No acórdão da decisão n. 70067817189, a responsabilidade solidária entre os entes federados é permissiva para que “[...] o cidadão exija, em conjunto ou separadamente, o cumprimento da obrigação por qualquer dos entes públicos [...]"12 (RIO GRANDE DO SUL, 2016), independentemente das competências regionais ou hierarquizadas do Sistema de Saúde brasileiro.

Entendimento comum é da Quarta Câmara Cível, no julgado 70066109497, onde afasta a ilegitimidade passiva alegada pelos entes federados em apelação, uma vez consolidado o tema da responsabilidade solidária entre União, Estados e Distrito Federal, e Municípios no fornecimento de medicamentos.

É uníssono o discurso no tocante a responsabilidade solidária dos entes federados para o fornecimento de fármacos, entendimento esse pacífico no Tribunal de Justiça do Estado do Rio Grande do Sul, podendo ser averiguado no posicionamento dos desembargadores em inúmeros outros julgados (70067741769; 70067757989; 70067988428; 70067764852; 70067369652; 70067768119, dentre outros).

\subsubsection{Questões Organizacionais-administrativas do Sistema Único de Saúde como} Tese de Oposição ao Fornecimento dos Medicamentos

Preliminarmente, necessário fazer uma exposição sobre o que seria a divisão administrativa ou questões organizacionais do Sistema Único de Saúde (SUS). É sabido que dois princípios basilares que disciplinam o funcionamento do Sistema de saúde são a 
O entendimento jurisprudencial do Tribunal de Justiça do Rio Grande do Sul sobre o fornecimento judicial de medicamentos

regionalização e descentralização, ou seja, as ações de saúde devem ser dirigidas regionalmente, inter-relacionando-se com a descentralização de competências ${ }^{13}$.

Destarte, no tocante aos medicamentos, a divisão de competências para o fornecimento dos fármacos tem fulcro na Portaria 1.554/2013 (BRASIL, 2013), onde a competência dos entes federados resta partida em três grupos. O Grupo I diz respeito aos medicamentos de competência de aquisição/financiamento do Ministério da Saúde/União; o grupo II são aqueles de responsabilidade dos Estados e Distrito Federal; e o grupo III, aqueles de responsabilidade dos Municípios e Distrito Federal (por cumular competência de Estados e Municípios).

São listas gigantescas com relação de inúmeros medicamentos a que cada ente, com base nessa portaria, é responsável de fornecer para os cidadãos. Essa questão organizacional ou divisão administrativa que é aqui tratada.

Cumpre frisar o entendimento dispensado no acórdão 70067742288, onde a divisão de competências dentro do SUS, propriamente aquele administrativa, onde é postulado quais os fármacos pelo qual cada ente é responsável, é posto em segundo plano, em razão de posicionamento que "[...]entende que o Sistema de Saúde é único e, por consequência, solidário, o que faz com que respondam por ele os três níveis da administração - federal, estadual e municipal [...]" (RIO GRANDE DO SUL, 2016) ${ }^{14}$.

Ademais, no tocante a divisão administrativa de competências, conseguiu-se extrair da análise que as repartições de competências entre os entes administrativos somente podem ser opostas entre si, não perante o cidadão, ou seja, a essa repartição é oponível em uma relação entre entes federados, não entre ente e cidadão ${ }^{15}$.

Assim, em relação ao item anterior - responsabilidade solidária -, as questões de administração interna do Sistema de Saúde e sua consequente (des)organização não podem sobrepor-se a responsabilidade solidária dos entes no fornecimento do medicamento, bem como onerar o cidadão na tutela requerida.

\subsubsection{Avaliação Jurisprudencial quanto à Eficácia do Tratamento Pleiteado pelo}

\section{Cidadão}

Mostra-se com o julgado da 20ª Câmara Cível, no acórdão 70067852426, a preocupação ou cuidado na concessão de tratamentos postulados, averiguando o tocante a eficácia do pleiteado pela parte. Nesse julgado, a câmara reconhece a possibilidade de fornecimento de medicamento pelos entes quando não puder ser utilizado o medicamento fornecido pelo SUS, no entanto, em razão de laudos e pareceres do Departamento Médico 
Judiciário em que não ratifica a eficácia do medicamento postulado, tem o Tribunal se posicionado pelo não acolhimento da pretensão.

Corrobora esse entendimento o julgado 70067488593 da 4a Câmara Cível, onde o parecer da Equipe de Consultores do Estado preponderou sob aquele juntado na inicial pela autora em razão da não comprovação da eficácia do tratamento postulado pela autora, negando provimento ao recurso, onde a sentença na origem também foi improcedente.

Destarte esse entendimento, o julgado 70067657320, da 20ª Câmara Cível destacou que embora a Equipe de Consultores do Estado diga que há possibilidade de substituição do fármaco por um disponível na listagem do SUS, ainda assim deve prevalecer a prescrição do médico que acompanha o paciente e a evolução do seu quadro de saúde.

O que se denota aqui são duas posições que vão de encontro com a preservação da vida, do melhor interesse ao cidadão e da preocupação com seu direito fundamental à saúde. Um primeiro que é o posicionamento pelo não provimento de medicamento que não tem comprovação efetivamente comprovada. E um segundo que defende o laudo do médico que acompanha a paciente desde os primórdios da enfermidade sob àquele formulado pela Equipe ou médicos do Juízo.

\subsubsection{A Oposição da Reserva do Possível e do Princípio da Separação dos Poderes}

O instituto da Reserva do Possível, como visto de modo sintético no capítulo dois desse trabalho tem seu surgimento na Alemanha, em 1970 (FIGUEIREDO, SARLET, 2016, p. 188). Naquela oportunidade, a Reserva do Possível poderia ser considerada como “[...] o que pode o indivíduo 'racionalmente' exigir da sociedade" (ATAUALPA, MORAIS, 2015, p. 4), bem como a capacidade jurídica e a disponibilidade efetiva de recursos para atendimento do pleito do cidadão (FIGUEIREDO, SARLET, 2016, p. 189).

De certo, não é um conceito pacífico que possa ter uma definição sólida na doutrina, mas seu espírito engloba as três perspectivas tratadas, quais sejam a disponibilidade de recursos, a capacidade jurídica (referente a questões administrativas de competência) e racionalidade do pedido, ou proporcionalidade e razoabilidade da prestação (FIGUEIREDO, SARLET, 2016, p. 189).

Quanto ao princípio da separação dos poderes, esse não é criação nova, mas encontra respaldo nos ideais de Locke e Montesquieu ${ }^{16}$. Desse modo, embora não se R. Fac. Dir. UFG, v. 41, n.2, p.69-86, maio / ago. 2017 
O entendimento jurisprudencial do Tribunal de Justiça do Rio Grande do Sul sobre o fornecimento judicial de medicamentos

vislumbre uma definição desse princípio estático à compreensão clássica, a fim de balizar o entendimento aqui pretendido, poder-se-ia propor o entendimento de que entre a atuação dos três poderes existe uma fronteira, onde ficam nítidas as funções de cada um deles.

Entretanto, bem alerta Gervasoni e Leal que esse conceito ou concepção deve sofrer o approach do tempo em que está inserida, com todos os desdobramentos políticos e jurídicos atuais, muito em razão da "[...] mudança e do caráter paradigmático da interpretação jurídica [...]” (GERVASONI; LEAL, 2011, p. 114), entendo esse conceito desenhado como concepção apriorística.

Feitas essa base teórica, passa-se às análises. Na decisão $70067757989^{17}$, a $21^{a}$ Câmara Cível analisa questões pontuais, especificamente os institutos do Princípio da Separação dos Poderes e a Reserva do Possível. O julgado posiciona-se no sentido de que “A saúde não pode esperar e há obrigação dos entes públicos de se programar para tais situações" ${ }^{\prime 18}$, afastando a ausência de dotação orçamentária como causa para o não fornecimento.

Ainda, quanto a Separação de Poderes, elenca o art. $5^{\circ} \mathrm{XXXV}$ da $\mathrm{CF}^{19}$, a fim de defender que o Poder Judiciário não interfere nos demais poderes, por tal apreciação da demanda constituir direito fundamental do cidadão e dever fundamental constitucionalmente posto.

Ademais, a Reserva do Possível é contrastada com o mínimo existencial, sendo esse último preponderante sobre aquele, ou seja, não pode a Reserva do Possível incidir onde "[...] o Poder Público tem a obrigação constitucional de garantir condições mínimas de saúde aos seus tutelados [...]"20.

Complementarmente, o julgado 70067967885 afirma que essas questões suscitadas (dotação orçamentária, reserva do possível ou separação dos poderes) não podem ser ordem retórica sedimentada no senso comum das alegações dos entes federados para escusa ou negativa da prestação buscada pelo cidadão.

Ainda, no julgado 70066545096, o colegiado foi categórico ao afirmar que "Não se pode permitir que a burocracia e as dificuldades financeiras vençam o direito à saúde, que se sobrepõe a todos os demais" $" 21$.

Almejando um ponto de equilíbrio dessas concepções, o acórdão 70067794586, exprime a ideia e a realidade da finitude dos recursos públicos, devendo esses serem canalizados com economia, a fim de não onerar “de graça” os cofres públicos, garantindo os princípios da eficiência, acesso universal e igualdade. 


\subsubsection{Outras variantes jurisprudenciais}

Como é impossível desenvolver todas as teses e entendimentos oriundos do estudo dos acórdãos de maneira sucinta, importante, portanto, a fim de sofisticar o levantamento dos resultados, abrir este tópico incidente para ressaltar outros temas importantes que arquitetam o posicionamento do Tribunal quanto o direito à saúde e suas tangentes.

Inúmeros acórdãos ${ }^{22}$ trouxeram o aspecto da real necessidade do tratamento postulado e a comprovada hipossuficiência ou carência financeira do autor para postular o fornecimento judicial do medicamento. Essas duas condicionantes, no atual cenário crítico brasileiro em todas as esferas, servem para direcionamento dos recursos financeiros a quem deles realmente necessita, e que não possui condições econômicas de arcar privadamente com o medicamento postulado.

Ainda assim, verifica-se, na análise caso a caso, a real necessidade do tratamento ora pleiteado, sendo que, se ineficaz, ou havendo possibilidade de substituição por um disponibilizado pelo sistema, tal pretensão não ganha provimento jurisdicional.

De certo, que essa preocupação do Tribunal com prover medicamentos a quem deles realmente necessite e não tenha condição de arcar financeiramente vai de encontro com um orçamento estatal estourado, com enormes rombos, precário, demonstrando, de uma perspectiva, uma angústia panorâmica pela situação do Estado, que além propriamente da função jurisdicional que lhe cabe, visa colaborar com a administração pública no direcionamento de recursos.

\section{CONSIDERAÇÕES FINAIS}

A Judicialização assumiu papel de destaque no cenário jurídico brasileiro, tal afirmativa não parece encontrar grandes divergências. Esse munício do cidadão para garantir seu direito, seja ele qual for, aqui nesse trabalho o direito fundamental à saúde em enfoque, é imprescindível para que os direitos fundamentais, em alguma medida, mas não a ideal, aufiram um grau satisfatória de efetividade.

No entanto, nessas considerações finais, mesmo que de maneira incidental e secular, é necessário tecer uma visão crítica sobre essa massa de ajuizamentos. Uma das principais críticas, a Judicialização, em sua acepção majoritária, busca resolver lides individuais, ou seja, entre cidadão e Estado (União, Estados e Municípios), efetivando direitos inter partes, ou seja, principalmente nos direitos sociais em que se vislumbra a R. Fac. Dir. UFG, v. 41, n.2, p.69-86, maio / ago. 2017 
O entendimento jurisprudencial do Tribunal de Justiça do Rio Grande do Sul sobre o fornecimento judicial de medicamentos

sua irradiação de efetividade para um âmbito coletivo, a Judicialização não contribui muito para a realização desse direito no sentido erga omnes.

Derradeiramente, um déficit na execução e administração das políticas públicas, que não atinge parcela dos cidadãos que necessitam do apoio estatal por meio do provimento de medicamentos, tratamentos ou procedimentos cirúrgicos, por exemplo, enseja que esses mesmos indivíduos busquem o Poder Judiciário para que tenham o seu direito fundamental deferido.

O provimento jurisdicional, consciente do seu papel no sistema jurídicopolítico brasileiro, bem como com a responsabilidade que tem com a Constituição, devendo garantir-lhe efetividade, sem olvidar a responsabilidade com a sociedade num todo (incluindo outras dimensões como a política e econômica), mostrou que é imperativa a análise caso a caso, atentando para inúmeras variantes que podem existir na tríade cidadão-pretensão-estado.

E no estudo dos julgados pode se verificar que o direito à saúde é direito fundamental-social, de responsabilidade solidária dos entes federados no fornecimento ${ }^{23}$, dando primazia ao laudo médico do médico que acompanha o paciente a médio e longo prazo, contudo, buscando atentar para a prioridade pelo tratamento que integra os programas do Sistema Único de Saúde (SUS) ${ }^{24}$ possibilidade de substituição do medicamento prescrito por um similar que integre a lista de medicamentos fornecidos pelo SUS, a hipossuficiência econômica e real necessidade do tratamento postulado pelo cidadão.

O objetivo deste trabalho foi demonstrar como o direito fundamental à saúde está posicionado no entendimento do Tribunal de Justiça do Estado do Rio Grande do Sul, isso justificado pelo déficit da realização das políticas públicas no país, que não realizam satisfatoriamente os direitos fundamentais pela via administrativa, e pela crescente Judicialização das demandas que envolvem esse direito, o que por si só já esteia a pesquisa acadêmica sobre o tema.

\section{REFERÊNCIAS}

ATAUALPA, Alexandre Selayaran; MORAIS, Fausto Santos de. Direito à saúde e reserva do possível. P. 4. IX Mostra de Iniciação Científica e Extensão Comunitária e VIII Mostra de Pesquisa de Pós-Graduação da IMED 2015. Disponível em $<$ http://soac.imed.edu.br/index.php/mic/ixmic/paper/view/184. Acesso em 29 de abril de 2017. 
BARBOSA, Jeferson Ferreira. Direito à saúde e solidariedade na Constituição brasileira. Porto Alegre: Livraria do Advogado, 2014.

BARROSO, Luís Roberto. Judicialização, ativismo judicial e legitimidade democrática. Revista [Syn]Thesis, Rio de Janeiro, vol. 5, n.1, p. 23-32, 2012.

Neoconstitucionalismo e constitucionalização do direito. P. 15. Disponível em <http://www.luisrobertobarroso.com.br/wpcontent/themes/LRB/pdf/neoconstitucionalismo_e_constitucionalizacao_do_direito_pt.p df>. Acesso em 23 de abril de 2017.

Da falta de efetividade à judicialização excessiva: direito à proteção da saúde, fornecimento gratuito de medicamentos e parâmetros para atuação judicial. Revista Interesse Público, Belo Horizonte, n, 46, novembro/dezembro 2007.

BRASIL. Constituição da República Federativa do Brasil de 1988. Disponível em <www.planalto.gov.br/ccivil_03/constituicao/constituicaocompilado.htm>. Acesso em 29 de abril de 2017.

Lei n. 8.080, de 19 de setembro de 1990. Disponível em <http://www.planalto.gov.br/ccivil_03/leis/L8080.htm>. Acesso em 29 de abril de 2017.

Supremo Tribunal Federal. Agravo Regimental em Suspensão de Tutela Antecipada n. 175, Relator: Gilmar Mendes, julgado em 16 de junho de 2009. Disponível em <http://www.stf.jus.br/arquivo/cms/noticianoticiastf/anexo/sta175.pdf>. Acesso em 29 de abril de 2017.

Ministério da Saúde. Portaria n⿳ 1.554, de 30 de julho de 2013. Disponível em <http://bvsms.saude.gov.br/bvs/saudelegis/gm/2013/prt1554_30_07_2013.html>. Acesso em 27 de abril de 2017.

CONJUR. Com 113 mil processos, TJ-RS lidera demandas envolvendo a área da saúde. Matéria veiculada em 11 de agosto de 2014. Disponível em <http://www.conjur.com.br/2014-ago-11/1139-mil-processos-tj-rs-lidera-demandasarea-saude>. Acesso em 29 de abril de 2017.

FERREIRA, Marina Costa. Direito à proteção da saúde pela via judicial: em busca de efetividade e equidade. Revista de Estudos Jurídicos, São Paulo, ano 15, n. 22, p. 235263, julho - dezembro de 2011.

FIGUEIREDO, Mariana Filchtiner; SARLET, Ingo Wolfgang. Reserva do possível, mínimo existencial e direito à saúde: algumas aproximações. Revista Direitos Fundamentais e Justiça, Porto Alegre, n. 1, outubro- dezembro 2007, p. 171-213.

GERVASONI, Tássia Aparecida; LEAL, Monica Clarissa Hennig; Neoconstitucionalismo e nova hermenêutica: novas perspectivas acerca da (i)legitimidade da jurisdição constitucional na concretização dos direitos à luz da teoria da separação dos poderes. Revista Direitos Fundamentais e Justiça, Porto Alegre, ano 5, n. 117, p. 96-117, outubro-dezembro 2011. 
O entendimento jurisprudencial do Tribunal de Justiça do Rio Grande do Sul sobre o fornecimento judicial de medicamentos

HACHEM, Daniel Wunder. A dupla titularidade (individual e transindividual) dos direitos fundamentais econômicos, sociais, culturais e ambientais. Revista de Direitos Fundamentais e Democracia, Curitiba, v. 14, n. 4, p. 618-688, julho/dezembro de 2013.

NOVAIS, Jorge Reis. Direitos sociais: teoria jurídica dos direitos sociais enquanto direitos fundamentais. 1 ed. Coimbra: Coimbra Editora, 2010.

RIO GRANDE DO SUL. Constituição Estadual de 1989, promulgada em 03 de outubro de $1989 . \quad$ Disponível em: http://www2.al.rs.gov.br/dal/LinkClick.aspx?fileticket=WQdIfqNoXO4\%3d\&tabid=36 $83 \&$ mid=5359. Acesso em 29 de abril de 2017.

SARLET, Ingo Wolfgang. A eficácia dos direitos fundamentais: uma teoria geral dos direitos fundamentais na perspectiva constitucional. 11 ed. Porto Alegre: Livraria do Advogado, 2012.

SARLET, Ingo Wolfgang. Curso de direito constitucional. $3^{a}$ ed. São Paulo: Revista dos Tribunais, 2014.

STAFFEN, Marcio Ricardo; LANGER, Octaviano. Considerações sobre a exigibilidade judicial dos direitos sociais em um Estado Democrático de Direito. Revista de Estudos Jurídicos, São Paulo, ano. 15, n. 22, p. 389-409, julho - dezembro de 2011.

VIEIRA, Oscar Vilhena. Supremocracia. Revista Direito GV, São Paulo, vol. 4, jul-dez 2008.

Artigo recebido em 25 de julho de 2017 e aceito em 25 de novembro de 2017

\footnotetext{
${ }^{1}$ Adotando a teoria de Jorge Reis Novais (2010, p. 42), os direitos sociais são aqueles direitos fundamentais que geram ao Estado o dever de respeitar, proteger e realizar os bens (jurídicos) inerentes à sociedade como um todo, quais sejam, por exemplo, o direito à saúde e o direito à educação. Desse conceito, analiticamente se extrai uma concepção de uma seara negativa dos direitos sociais (além da já conhecida dimensão positiva), ao passo que, de acordo com esse conceito de Novais, o Estado tem o dever de proteger os direitos sociais.

${ }^{2}$ A lei 8.080/90 (BRASIL, 1990), conhecida como Lei Orgânica da Saúde, que dispõe sobre todo funcionamento do Sistema Único de Saúde (SUS) em seu artigo $2^{\circ}$ coloca o direito à saúde como direito fundamental, bem como frisa o dever do Estado nessa promoção, proteção e recuperação, ressaltando nesse dizer a natureza negativa e positiva desse direito. Assim como a Constituição Estadual do Rio Grande do Sul dispõe no art. 241: “Art. 241. A saúde é direito de todos e dever do Estado e do Município, através de sua promoção, proteção e recuperação. Parágrafo único. $\mathrm{O}$
} 
dever do Estado, garantido por adequada política social e econômica, não exclui o do indivíduo, da família e de instituições e empresas que produzam riscos ou danos à saúde do indivíduo ou da coletividade" (RIO GRANDE DO SUL, 1989).

${ }^{3} \mathrm{O}$ artigo $5^{\circ}, \S 1^{\circ}$ da Constituição Federal define que as normas de direitos fundamentais têm aplicabilidade imediata, acentuando Sarlet (2012, p. 58) que tal característica é ponto diferencial e de deferência dos direitos fundamentais, pois atribui aos direitos fundamentais uma "juridicidade reforçada", diferenciando-os das demais normas constitucionais, e causando destaque no sistema constitucional brasileiro. Ainda, em razão desse princípio (da aplicabilidade imediata) enseja uma juridicidade diretamente aplicável, da mesma forma, como ocorre, então com o direito fundamental social à saúde, que em ineficiência (omissão ou ação insuficiente) das políticas públicas, enseja uma tutela jurisdicional de tal direito (daí também porque podem os direitos fundamentais ser justiciáveis).

${ }^{4}$ A dimensão subjetiva consubstancia-se, como premissa geral, direitos do indivíduo em face do obrigado (Estado) a prestação de um direito fundamental. Nessa perspectiva, a dimensão subjetiva, em sentido amplo, "[...] engloba a possibilidade de o titular do direito fazer valer judicialmente os poderes, as liberdades, ou mesmo o direito à ação ou ações negativas ou positivas que lhe foram outorgadas pela norma consagradora de um direito fundamental [...]" (SARLET, 2014, p. 309). Outro aspecto peculiar dessa dimensão é o "[...] o estabelecimento de uma relação jurídica bem definida entre cidadão e Estado e atribuição de uma posição subjetiva àquele [...]" (HACHEM, 2013, p. 633), ou seja, um poder exigir do Estado o direito fundamental incluído na esfera jurídica do indivíduo.

5 Abordagem no texto de sua autoria "Judicialização, ativismo judicial e legitimidade democrática”. In: Revista [Syn]Thesis, Rio de Janeiro, vol. 5, n.1, p. 23-32, 2012.

${ }^{6}$ Sobre esse espírito da Constituição Brasileira de 1988, Vieira (2008, p. 446) aponta que "[...] a Constituição transcendeu os temas propriamente constitucionais e regulamentou pormenorizada e obsessivamente um amplo campo das relações sociais, econômicas e públicas, em uma espécie de compromisso maximizador".

${ }^{7}$ Matéria veiculada no dia 11 de agosto de 2014, no sítio do Consultor Jurídico, intitulada "Com 113 mil processos, TJ-RS lidera demandas envolvendo a área da saúde”. Disponível em $<$ http://www.conjur.com.br/2014-ago-11/1139-mil-processos-tj-rs-lidera-demandas-areasaude>. Acesso em 29de abril de 2017.

${ }^{8}$ Luís Roberto Barroso (2007) versa sobre elas no artigo "Da falta de efetividade à judicialização excessiva: direito à proteção da saúde, fornecimento gratuito de medicamentos e parâmetros para atuação judicial"

${ }^{9}$ Langer e Staffen (2011, p. 396) corroboram tal entendimento, elucidando que “[...] o Judiciário como poder comprometido com os ideais constitucionais do Estado, em se constatando a inércia dos poderes públicos na realização de políticas e ações sociais determinadas constitucionalmente, 'a via judiciária se apresenta como a via possível para realização de direitos que estão previstos nas leis e na Constituição"”.

10

http://www.tjrs.jus.br/busca/?tb=jurisnova\&partialfields=tribunal $\% 3 \mathrm{ATribunal} \% 2520 \mathrm{de} \% 2520 \mathrm{~J}$ usti $\% 25 \mathrm{C} 3 \% 25 \mathrm{~A} 7 \mathrm{a} \% 2520 \mathrm{do} \% 2520 \mathrm{RS}$.(TipoDecisao\%3Aac\%25C3\%25B3rd\%25C3\%25A3o| TipoDecisao\%3Amonocr\%25C3\%25A1tica|TipoDecisao:null)\&t=s\&pesq=juris .

11 Foram analisadas as seguintes decisões: 70067817189, 70066109497, 70067852426, 70067839001, 70067742288, 70067574699, 70067757989, 70067826354, 70067741769, 70067988428, 70067764852, 70067369652, 70067462028, 70067768119, 70067696906, R. Fac. Dir. UFG, v. 41, n.2, p.69-86, maio / ago. 2017

ISSN 0101-7187 
O entendimento jurisprudencial do Tribunal de Justiça do Rio Grande do Sul sobre o fornecimento judicial de medicamentos

$70065924904,70067488593,70067634410,70065813248,70067815548,70067820373$, 70067230367, 70067657320, 70067824920, 70067215939, 70067723627, 70067702118, 70067649293, 70067569640, 70067568642, 70066808510, 70067367946, 70067394825, 70097481093, 70067706069, 70067498774, 70067626994, 70067819466, 70067439893, 70067647073, 70067794586, 70067441865, 70067552133, 70067452961, 70066814941, 70063613830, 70067731851, 70067533729, 70067477562, 70067309666, 70067500884, $70067544759,70067821173$.

${ }^{12}$ RIO GRANDE DO SUL. Tribunal de Justiça do Rio Grande do Sul. Acórdão. Apelação Cível n. 70067817189, Vigésima Primeira Câmara Cível, Relator: Marco Aurélio Heinz, julgado em 24 de fevereiro de 2016

${ }^{13}$ Jeferson Ferreira Barbosa (2014, p. 73-74), em seu livro "Direito à saúde e solidariedade na Constituição Brasileira" traz um panorama sobre essa cenário de secularização da competência administrativa tripartite do sistema de saúde, onde ressalta que em estudo de processos movidos contra Secretaria Municipal de Saúde de São Paulo, pode ser analisado a "[...] desconsideração da organização tripartite, consistente na aquisição, pelo município, de medicamentos da lista do estado [...]", bem como ainda ressalta o caso do Espírito Santo, onde a Secretaria do Estado fora condenada a adquirir medicamentos de competência do município.

${ }^{14}$ RIO GRANDE DO SUL. Tribunal de Justiça do Rio Grande do Sul. Acórdão. Apelação Cível n. 70067742288, Vigésima Primeira Câmara Cível, Relator: Almir Porto da Rocha Filho, julgado em 24 de fevereiro de 2016.

15 Barbosa (2014, p. 80-81) traz argumentos favoráveis a repartição de competências administrativas dos entes federados. Afirma que a escolha do polo passivo da demanda não deva ser pelo arbítrio da parte requerente, mas sim de quem estivesse "[...] institucionalmente obrigado". Ainda, outro tópico que defende essa corrente é a negativa administrativa de fornecimento do medicamento pleiteado, ou seja, o cidadão deveria ingressar no Judiciário contra quem efetivamente, comprovando mediante uma certidão negativa, negou-lhe a medicação. Cumpre ressaltar que empiricamente essa última questão ocorre na prática. Os cidadãos instruem o seu processo para pedido de medicamentos com as negativas das Secretaria Municipal e Estadual de Saúde, embora, nos últimos anos, a negativa efetivamente dita (aquele que diz, ipsis literis, que o Estado ou Município não fornece o medicamento X, por exemplo) vêm sendo substituída por tabela de estoque de fármacos, a quantidade zero em estoque do medicamento pretendido, e isso nem sempre é aceito pelo juiz para análise de uma liminar.

${ }^{16}$ Gervasoni e Leal (2011, p. 111) destacam que o pensamento de Montesquieu que acreditava que tudo estaria perdido se um mesmo homem, ou então um mesmo órgão exercesse as três funções hoje compreendidas como Poder Executivo, Legislativo e Judiciário.

${ }^{17}$ RIO GRANDE DO SUL. Tribunal de Justiça do Rio Grande do Sul. Acórdão. Apelação Cível n. 70067757989, Vigésima Primeira Câmara Cível, Relator: Almir Porto da Rocha Filho, julgado em 24 de fevereiro de 2016.

${ }^{18}$ RIO GRANDE DO SUL. Tribunal de Justiça do Rio Grande do Sul. Acórdão. Apelação Cível n. 70067757989, Vigésima Primeira Câmara Cível, Relator: Almir Porto da Rocha Filho, julgado em 24 de fevereiro de 2016.

${ }^{19}$ Art. $5^{\circ}$ [...] XXXV - a lei não excluirá da apreciação do Poder Judiciário lesão ou ameaça a direito (BRASIL, 1988).

${ }^{20}$ RIO GRANDE DO SUL. Tribunal de Justiça do Rio Grande do Sul. Acórdão. Apelação Cível n. 70067757989, Vigésima Primeira Câmara Cível, Relator: Almir Porto da Rocha Filho, julgado em 24 de fevereiro de 2016. 
${ }^{21}$ RIO GRANDE DO SUL. Tribunal de Justiça do Rio Grande do Sul. Acórdão. Apelação Cível n. 70066545096, Vigésima Primeira Câmara Cível, Relator: Almir Porto da Rocha Filho, julgado em 24 de fevereiro de 2016.

22 Acórdãos 70067852426; 70067839001; 70067757989; 70067988428; 70067768119; 70067696906; 70067820373, dentre outros.

23 "O fato de o Sistema Único de Saúde ter descentralizado os serviços e conjugado os recursos financeiros dos entes da Federação, com o objetivo de aumentar a qualidade e o acesso aos serviços de saúde, apenas reforça a obrigação solidária e subsidiária entre eles" (BRASIL, 2009, p. 14).

24 "Dessa forma, podemos concluir que, em geral, deverá ser privilegiado o tratamento fornecido pelo SUS em detrimento de opção diversa escolhida pelo paciente, sempre que não for comprovada a ineficácia ou a impropriedade da política de saúde existente" (BRASIL, 2009, p. 22-23). 